Research Laboratories; Mr. C. C. Paterson, of the General Electric Co., Ltd.; Prof. R. Whiddington, of the University of Leeds; Dr. R. H. Pickard, of the British Cotton Industry Research Association; and Prof. J. A. Crowther, of the University of Reading. After the tea interval, the meeting was opened for general discussion. The important suggestions and comments made at the meeting and in writing are receiving the most careful consideration of the Board of the Institute, which it is anticipated will issue a memorandum on the subject in due course.

\section{Salmon and Freshwater Fisheries}

INFORMaTION given in the Report for the Year 1934 of the Ministry of Agriculture and Fisheries Salmon and Freshwater Fisheries (H.M. Stationery Office, $1 s$. net) shows that, on the whole, despite the prolonged period of drought during the summer months of that year, no disasters of a widespread character took place. The droughty conditions have, however, inevitably affected the catch of fish to a certain extent and led to incidents of mortality from pollution of one kind or another. Although the mortality of fish attributable to furunculosis was comparatively slight, the Report wisely stresses the necessity for no relaxation of vigilance over the dangers of this disease and states that "it is regrettable that the Diseases of Fish Bill, after passing through the House of Lords, failed, owing to congestion of business in the House of Commons, to become law". There is evidence in the Report that increasing attention is being paid to problems of pollution which affect not only the fisheries, but also the use of rivers for water supply and as amenities for the general public. The appointment of an Inland Water Survey Committee will, it is hoped, produce additional information of value for the study of fishery problems by the gauging of streams and correlation of their flow with rainfall. It is satisfactory to note that the large amounts spent on sewage disposal during the last few years appear to be benefiting many rivers. There is, however, still much work to be done in this direction, and it is pointed out that sewage was probably the cause of more cases of fish destruction than resulted from industrial effluents.

\section{Research in the Electrical Industry}

THE main object of the British Electrical and Allied Industries Research Association, 15 Savoy Street, W.C.2 (the E.R.A.), is the co-operation of all sections of the electrical industry and of all those associated with it, in the general interests, of the industry and in the national interest. The sections include manufacturers of electric plant, those who supply electricity, those who make extensive use of it and scientific and technical investigators. The desired results, namely, industrial expansion and public benefit, can only be attained by team work of the highest order. The Association is well supported by the industries affected. During the last five years, the income has increased from $£ 31,600$ to $£ 65,840$. The main work done is to increase the efficiency and trustworthiness of electrical apparatus and of electrical supply. A reduction of cost is for the public benefit, and this can be achieved by expanding the field of utility and increasing the use and demand. Among other researches carried out was one on the thermal stability and ignitability of dielectrics. A range of standard heat sources was devised to simulate the conditions which occur in practice. The method of applying those heat sources when testing insulating materials for resistance to applied heat and the grading of them is described in a new report (Ref. $L / 64$ ) issued during the year. A novel feature of interest is the standard flame, produced by a spirit burner of the Barthel type, which is reproducible to a degree of accuracy not possible with the Méker gas burner which it replaces. An extension of this work is in progress on the behaviour of ignitable materials under different ambient conditions, such as draught, with the object of devising means whereby self-extinguishing materials may be graded to better advantage.

\section{Sixth International Congress for Scientific Management}

THE Proceedings of the Sixth International Con. gress for Scientific Management, which have now been published (London: P. S. King and Son, Ltd.), completes the series of seven volumes containing the papers and speeches at the Congress. The six volumes issued prior to the Congress contained the papers to be presented at the various sectional meetings. The final volume includes reports on the actual discussions, and the excellent summaries of the rapporteurs give epitomes of the matter contained in the previous volumes. Full reports are given of the speeches at the first plenary sessions when "Management Problems arising from Government Intervention" were discussed. In the Educational and Training Section, the scientific worker will find much that is of interest in the discussions on sources of recruitment and methods of selection, which ranged over a wide field of personnel problems, and on objects and methods of training and further education, or on the avoidance of excess and waste of personnel selected and trained for high administrative positions. The wider use in administrative work of technical and scientific workers possessing administrative ability, while an urgent need in industry as in Government to-day, is only part of the general question of encouraging the development and securing the best selection of those possessing real administrative powers. The second plenary session, on the simplification of data, the place of statistics and the standardisation of terms, as well as various discussions in the manufacturing and agricultural sections, are also of considerable interest; for example, those on scientific methods applied to works management and on production control. For a volume designed as a permanent record, it is a pity that the subject index is so meagre.

\section{Compressed Gas as a Fuel for Motor Transport}

ON December 13, Mr. Robert Cook read a paper on "Compressed Gas as a Fuel for Motor Transport" before the East Midland Section of the Institute of Fuel and the Society of Chemical Industry at 